\title{
Avaliação patogênica in vitro de Pythium middletonii Sparrow e Pythium dissotocum Drechsler em alface
}

\author{
Filipe Rosa Baptista ${ }^{1}$; Carmen L. A. Pires-Zottarelli ${ }^{1}$; Liliane De Diana Teixeira ${ }^{2}$; Nelson Augusto dos Santos Júnior ${ }^{3}$
}

${ }^{1}$ Núcleo de Pesquisa em Micologia, Instituto de Botânica, C.P 3005, CEP 01061-970, São Paulo-SP. ${ }^{2}$ Departamento de Entomologia, Fitopatologia e Zoologia Agrícola, ESALQ/USP Piracicaba-SP. ${ }^{3}$ Núcleo de Pesquisa em Sementes, Instituto de Botânica, São Paulo-SP. Parte da Dissertação de Mestrado do primeiro autor .

Autor para correspondência: Filipe Rosa Baptista (filiperbaptista@yahoo.com.br)

Data de chegada: 31/03/2008. Aceito para publicação em: 04/02/2011.

\section{RESUMO}

Baptista, F.R.; Pires-Zottarelli, C.L.A.; Teixeira, L.D.; Santos Júnior, N.A.. Avaliação patogênica in vitro de Pythium middletonii Sparrow e Pythium dissotocum Drechsler em alface. Summa Phytopathologica, v.37, n.1, p.52-58, 2011.

Infecções radiculares nos cultivos hidropônicos de alface são frequentes e, na maior parte das vezes, causadas por espécies de Pythium, extremamente bem adaptadas ao ambiente aquático. Este estudo buscou avaliar o potencial patogênico in vitro de Pythium middletonii e $P$. dissotocum, em quatro cultivares de alface: Elisa (lisa), Vera (crespa), Mimosa (mimosa) e Tainá (americana). Sementes de alface, de cada cultivar, foram desinfetadas superficialmente, pré-germinadas por 24 horas, e colocadas na superfície do meio ágar-água. Em seguida, um disco de micélio dos isolados de Pythium, foi disposto no centro de cada placa. Placas contendo apenas as sementes de alface serviram como controle. O delineamento experimental utilizado foi inteiramente casualizado, com cinco repetições, sendo cada uma delas representada por uma placa de Petri. Avaliou-se o comprimento dos hipocótilos, das radículas e a porcentagem das plântulas sobreviventes após dez dias de incubação. O experimento foi conduzido na temperatura ideal de crescimento da alface $\left(20^{\circ} \mathrm{C}\right)$, e nas ideais para o crescimento dos isolados, $23^{\circ} \mathrm{C}$ para $P$. middletonii e $27^{\circ} \mathrm{C}$ para $P$. dissotocum. A $20^{\circ} \mathrm{C}$, P. dissotocum foi mais patogênico que $P$. middletonii, reduzindo significativamente o comprimento dos hipocótilos e, principalmente, das radículas, de praticamente todas as cultivares. Na temperatura de $27^{\circ} \mathrm{C}, P$. dissotocum foi responsável pela mais baixa porcentagem de plântulas sobreviventes entre as cultivares, sendo mais patogênico em Vera $(54 \%$ de sobrevivência). Dentre as cultivares analisadas, a Mimosa mostrou tendência de menor suscetibilidade a este patógeno, apresentando a maior porcentagem de plântulas sobreviventes e o maior comprimento das radículas em relação ao controle. $P$. dissotocum apresentou maior crescimento micelial e foi mais patogênico que $P$. middletonii em todos os experimentos realizados.

Palavras-chave adicionais: Pythium spp., Lactuca sativa L., hidroponia, patogenicidade

\section{ABSTRACT}

Baptista, F.R.; Pires-Zottarelli, C.L.A.; Teixeira, L.D.; Santos Júnior, N.A.. In vitro pathogenic evaluation of Pythium middletonii Sparrow and Pythium dissotocum Drechsler in lettuce. Summa Phytopathologica, v.37, n.1, p.52-58, 2011.

Root infections in hydroponic lettuce are frequent and mostly caused by Pythium species, which are extremely well adapted to aquatic environments. The present study aimed to evaluate in vitro the pathogenic potential of Pythium middletonii and Pythium dissotocum in four cultivars of lettuce, Elisa (smooth), Vera (curly), Mimosa (mimosa) and Tainá (American). Lettuce seeds from each cultivar were superficially disinfected, pre-germinated for 24 hours and placed on the water agar medium surface. Then, a dish containing mycelium from Pythium isolates was placed in the center of each plate. Control consisted of plates containing lettuce seeds only. Experimental design was completely randomized, with five replicates, each one represented by a Petri dish. Hypocotyl and radical length besides surviving seedlings percentage after ten days of incubation were evaluated. The experiment was carried out, at different temperatures, and the pathogenicity of the isolates was investigated at the ideal temperature for the lettuce $\left(20^{\circ} \mathrm{C}\right)$, and at the ideal temperatures for the growth of the isolates, $23^{\circ} \mathrm{C}$ for $P$. middletonii and $27^{\circ} \mathrm{C}$ for $P$. dissotocum. At $20^{\circ} \mathrm{C}, P$. dissotocum had higher pathogenicity on lettuce cultivars than $P$. middletonii, significantly decreasing the length of hypocotyls, especially radicles, of most cultivars. For $P$. dissotocum, $27^{\circ} \mathrm{C}$ was the most suitable temperature for the specimen growth; however, it led to the lowest percentage of surviving seedlings among all cultivars, with the lowest percentage (54\%) detected for Vera. Among the cultivars, Mimosa presented higher percentage of survivor seedlings and higher length of radicles in relation to the control, and thus was considered less susceptible to the pathogen. P. dissotocum presented higher mycelium growth and was more pathogenic than P. middletonii in all experiments.

Palavras-chave adicionais: Pythium spp., Lactuca sativa L., hydroponics, pathogenicity 
A hidroponia $($ hydro $=$ água e ponos $=$ trabalho) é uma técnica relativamente antiga, mas mundialmente consolidada somente no final da década de 80, inclusive no Brasil, onde tem sido comum encontrar produtos hidropônicos em supermercados de grandes centros consumidores, sendo o estado de São Paulo o maior produtor $(11,25)$. Entre os fatores que contribuíram para uma significativa expansão da hidroponia encontram-se: a produção de hortaliças de ótima qualidade; o melhor aproveitamento de espaço físico, por permitir cultivos sucessivos; a menor incidência de pragas e doenças e, portanto, menor aplicação de tratamentos fitossanitários; o melhor controle do meio nutritivo para crescimento das plantas e o aproveitamento de água e nutrientes; além da menor contaminação do lençol freático por nitrogênio nítrico e outros elementos químicos, uma vez que a solução nutritiva recircula no sistema $(4,21)$.

No Brasil, há diversas culturas produzidas em sistemas hidropônicos, entretanto, a alface (Lactuca sativa L.) perfaz a preferência de $90 \%$ dos hidroponicultores, pois apresenta ciclo de vida curto, alta produtividade e ampla aceitação no mercado $(5,8)$. Apesar das vantagens anteriormente citadas, a alface é ainda fitopatologicamente pouco estudada no Brasil $(18,25)$. Infecções radiculares encontradas nos cultivos hidropônicos são frequentes e, na maior parte das vezes, causadas por espécies de Pythium, extremamente bem adaptadas ao ambiente aquático, onde encontram condições ideais para a sobrevivência e disseminação de seus esporos, não apresentando normalmente especificidade de hospedeiro $(7,19$, $22,25)$. Normalmente causam prejuízos consideráveis nos cultivos hidropônicos, sendo responsáveis pelo abandono da atividade de muitos produtores, sendo segundo Vanachter (27), uma grande limitação à expansão mundial da técnica NFT (Nutrient Film Technique).

Em cultivo hidropônico, as espécies de Pythium mais comumente citadas em literatura são: $P$. aphanidermatum (Edson) Fitzp, $P$. dissotocum Drechsler, P. intermedium de Bary, P. irregulare Buisman, P. myriotylum Drechsler, P. sylvaticum Campbell \& Hendrix, P. ultimum Trow e Pythium do grupo F (7, 15, 24, 26).

Estudos que abordam a presença de Pythium em sistemas hidropônicos são ainda escassos no Brasil, embora a presença de seus representantes venha sendo detectada há algum tempo $(23,24)$. Teixeira et al. (25) obtiveram doze isolados de Pythium de raízes de plantas de alface cultivada em diversos sistemas hidropônicos do estado de São Paulo e da Bahia. Dentre estes, os isolados pertencentes à $P$. helicoides Drechsler foram os mais patogênicos, ocasionando $100 \%$ de mortalidade das sementes logo após a germinação. Pinto et al. (16) estudaram a reação de cultivares de alface à podridão de raízes causada por $P$. helicoides em sistemas hidropônicos, concluindo que as cultivares crespas apresentaram menor número de plântulas sadias e menor comprimento das raízes e dos hipocótilos, mostrando maior suscetibilidade ao patógeno. Patekoski \& Pires-Zottarelli $(17,18)$ evidenciaram a patogenicidade de $P$. aphanidermatum e $P$. dissotocum em diferentes cultivares de alface. Em continuidade, analisaram a ação do produto Biotrich em duas das variedades, consideradas mais e menos suscetíveis ao patógeno mais agressivo, $P$. aphanidermatum, demonstrando que o produto in vitro não promoveu o crescimento das plantas, mas foi efetivo no controle do patógeno.

Tendo em vista que a alface é uma das hortaliças mais utilizadas na alimentação dos brasileiros, da frequente presença de isolados de Pythium como importantes patógenos em hidroponia, das significantes perdas verificadas em cultivos hidropônicos e da escassez de dados sobre o assunto no Brasil, o presente estudo teve como objetivo avaliar o potencial patogênico de Pythium middletonii Sparrow e P. dissotocum
Drechsler, espécies isoladas de cultivos hidropônicos, em diferentes cultivares comerciais de alface.

\section{MATERIAL E MÉTODOS}

Consultas realizadas na clínica fitopatológica da ESALQ-USP e no Núcleo de Pesquisa em Micologia do Instituto de Botânica pelos agricultores especializados em hidroponia do estado de São Paulo possibilitaram o isolamento e a identificação de Pythium dissotocum (Figura 1) e Pythium middletonii (Figura 2), isolados de raízes necrosadas de rúcula (Eruca sativa L.) hidropônica da região de Taubaté (SP) e de alface hidropônica da região de Pindamonhangaba (SP), respectivamente. $\mathrm{O}$ isolamento dos patógenos foi realizado de acordo com metodologia utilizada por Teixeira et al. (25), que consiste na lavagem das raízes necróticas, em água corrente, e posterior transferência de fragmentos radiculares para meio de cultura, tendo sido utilizado o CMA + p.p.e. (corn-meal ágar DIFCO acrescido de penicilina, pimaricina e sulfato de estreptomicina) (1). Após crescidos, os isolados foram transferidos para placa de Petri esterilizada adicionando água destilada esterilizada e duas metades de sementes previamente fervidas de Sorghum sp.

A identificação dos espécimes foi baseada nas características morfológicas dos isolados, como a presença ou não de dilatações hifálicas e haustórios; o tamanho e tipo dos zoosporângios; produção e formação dos zoósporos; forma, tamanho e posição dos oogônios; tamanho e condição aplerótica ou plerótica dos oósporos e número, forma e origem dos anterídios $(2,6,12,19,28)$. Os espécimes foram preservados em frascos "Wheaton" em câmara fria, com água destilada esterilizada (13) e pelo método de Castellani (3) e, em seguida, incorporados à Coleção de Culturas de Algas, Fungos e Cianobactérias do Instituto de Botânica de São Paulo (CCIBt).

\section{Influência da temperatura sobre o crescimento micelial dos} isolados

Após purificação dos isolados, discos de micélio de $6 \mathrm{~mm}$ diâm. foram retirados e colocados no centro de placas de Petri (90mm) contendo o meio de cultura ágar-água. As placas foram incubadas em câmaras de crescimento, em $15,20,25,30,35$ e $40^{\circ} \mathrm{C}$, com três repetições por temperatura. As leituras diárias foram realizadas a partir de 24 horas até o crescimento micelial total nas placas, medindo-se o diâmetro das colônias em 4 direções diametralmente opostas, com o auxílio de uma régua milimetrada, desprezando como leitura o dia em os isolados atingiram a extensão máxima da placa (4,5 cm raio), em virtude de não subestimar a velocidade de crescimento dos mesmos.

Para a análise dos resultados foram considerados os diâmetros médios das avaliações, com o estabelecimento da temperatura ideal de crescimento dos isolados sendo realizado por meio de uma equação de $2^{\circ}$ grau.

Avaliação patogênica in vitro de Pythium middletonii e $P$. dissotocum em quatro cultivares comerciais de alface

A avaliação da patogenicidade dos espécimes de Pythium middletonii e $P$. dissotocum foi realizada em laboratório, na temperatura ideal para o crescimento da alface, que é em torno de $20^{\circ} \mathrm{C}$ (14) e na temperatura ideal de cada isolado. Todos os experimentos foram realizados com o mesmo lote de cada uma das cultivares, tomando-se o cuidado de se avaliar anteriormente a uniformidade de germinação das sementes.

A metodologia utilizada para a avaliação patogênica in vitro foi a 

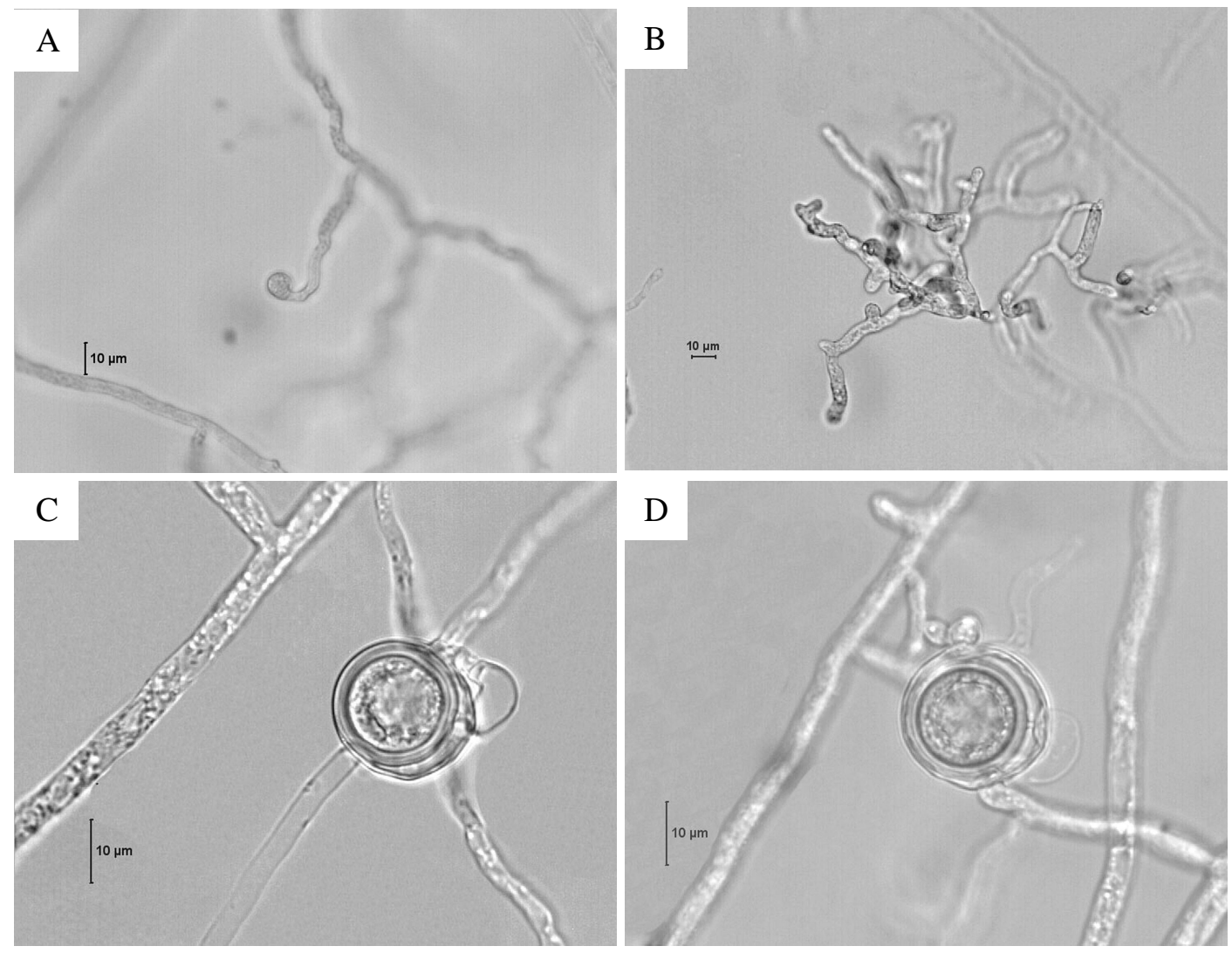

Figura 1. Pythium dissotocum. (A) Apressório; (B) Zoosporângio filamentoso não inflado; (C) Oogônio intercalar com anterídio monóclino; (D) Visualização do tubo de fertilização anteridial.

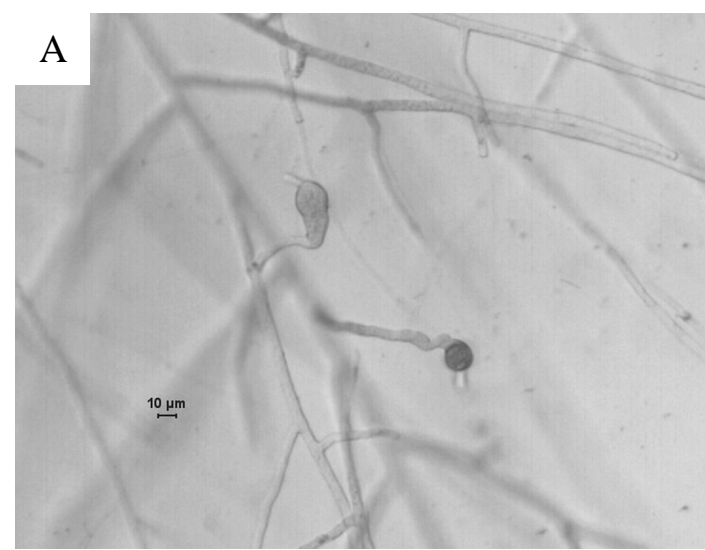

B
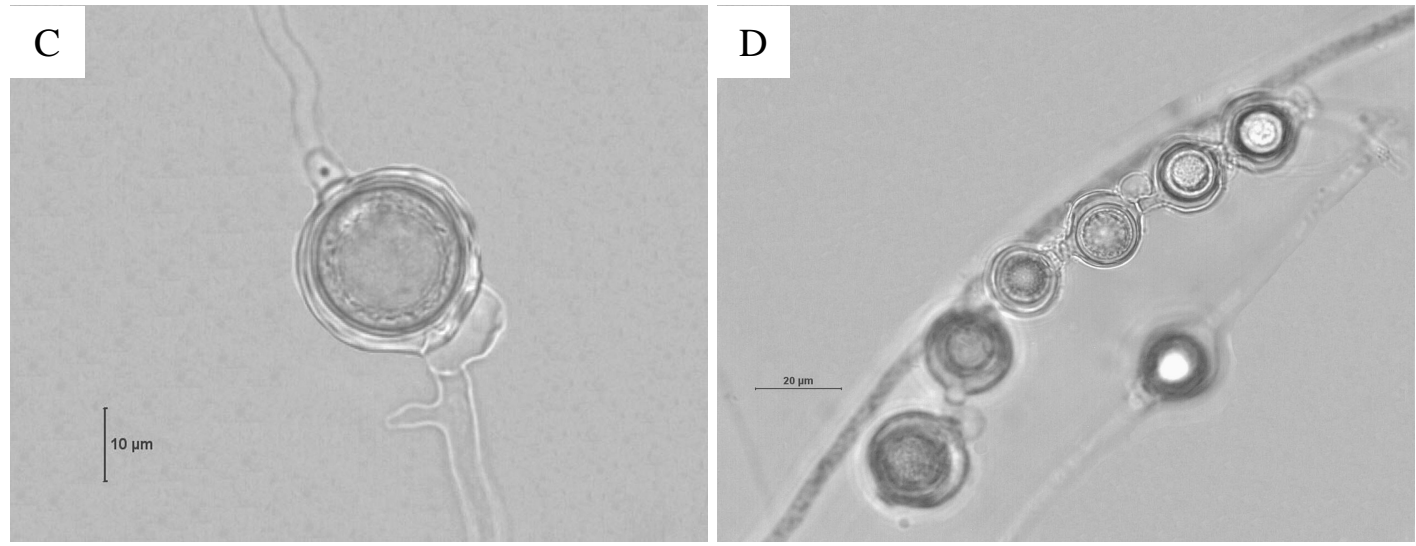

Figura 2. Pythium middletonii. (A) Apressórios; (B) Formação de oogônio dentro do zoosporângio; (C) Oogônio intercalar com anterídio monóclino séssil; (D) Oogônios catenulados. 
descrita em Teixeira et al. (25), na qual sementes de alface (sete sementes/ placa), das cultivares Elisa (lisa), Vera (crespa), Mimosa (mimosa) e Tainá (americana), após desinfestação superficial com hipoclorito de sódio (três partes de água destilada: uma parte de água sanitária $0,625 \%$ de cloro ativo), foram pré-germinadas por 24 horas em papel de filtro umedecido e colocadas na superfície de meio ágar-água, contido em placas de Petri, a aproximadamente $0,5 \mathrm{~cm}$ da borda das mesmas. Em seguida, um disco de $6 \mathrm{~mm}$ diâm. com micélio dos isolados de Pythium crescidos em CMA, foi disposto no centro de cada placa. Placas contendo apenas as sementes de alface em meio de cultura serviram como controle.

O delineamento experimental utilizado foi inteiramente casualizado, com cinco repetições, sendo cada repetição representada por uma placa de Petri. A incubação foi realizada por dez dias, segundo a Dra. Liliane D. D. Teixeira (comunicação pessoal), tempo ideal para o aparecimento de sintomatologia, utilizando para isso, câmara de crescimento com fotoperíodo de 12 horas de luz branca. O comprimento dos hipocótilos e das radículas foi mensurado por meio de uma régua graduada em centímetros, com concomitante avaliação da porcentagem das plântulas sobreviventes, segundo metodologia utilizada por Pinto et al. (16). Os dados foram analisados estatisticamente, por meio de análise de variância e as médias comparadas pelo teste de Tukey, a 5\% de probabilidade.

\section{RESULTADOS E DISCUSSÃO}

\section{Influência da temperatura sobre o crescimento micelial dos isolados}

A influência da temperatura sobre o crescimento micelial dos isolados foi avaliada por meio do crescimento micelial por tempo de incubação (dias) e pela taxa de extensão micelial (cmdia ${ }^{1}$ ) por temperatura de incubação $\left({ }^{\circ} \mathrm{C}\right)$. A temperatura demonstrou ser fator importante, influenciando nas diferenças obtidas entre o crescimento ideal e máximo dos espécimes estudados, sendo fundamental se estabelecer a temperatura ideal de crescimento para a posterior análise do potencial patogênico dos mesmos em condições de laboratório, embora se saiba que na natureza os espécimes de Pythium são fitopatogênicos em ampla gama de temperatura $(19,23)$.

Em todas as temperaturas avaliadas, observou-se um crescimento mais rápido do isolado de Pythium dissotocum em relação ao de $P$. middletonii. A temperatura ideal de crescimento de $P$. dissotocum foi de $27^{\circ} \mathrm{C}$ e máxima de $35^{\circ} \mathrm{C}$ e, de $P$. middletonii, a temperatura ideal foi de $23^{\circ} \mathrm{C}$ e a máxima de $30^{\circ} \mathrm{C}$. Não houve crescimento micelial de $P$. middletonii a partir de $35^{\circ} \mathrm{C}$, enquanto $P$. dissotocum não cresceu a $40^{\circ} \mathrm{C}$ (Figura 3 ).

Em $15^{\circ} \mathrm{C}$, Pythium dissotocum atingiu a extensão máxima das placas em três dias, enquanto $P$. middletonii desenvolveu-se mais lentamente, atingindo o crescimento total das placas em seis dias de incubação. Nesta temperatura os dois isolados se desenvolveram de forma mais vagarosa, sendo necessário mais tempo de incubação para atingirem a extensão máxima das placas. Em 20,25 e $35^{\circ} \mathrm{C}$, P. dissotocum atingiu o crescimento total nas placas em dois dias de incubação, enquanto na temperatura de $30^{\circ} \mathrm{C}$ o isolado atingiu a extensão máxima das placas em apenas um dia. Para $P$. middletonii, em 20 e $25^{\circ} \mathrm{C}$, houve aumento na velocidade de crescimento, tendo o isolado atingido o crescimento total nas placas em quatro e três dias, respectivamente; no entanto, em $30^{\circ} \mathrm{C}$, voltou a se desenvolver mais lentamente, finalizando o crescimento total nas placas em seis dias de incubação.
A influência da temperatura de incubação sobre a taxa de extensão micelial diária mostrou a melhor capacidade de $P$. dissotocum em desenvolver-se bem em diversas temperaturas em comparação ao isolado de P. middletonii, obtendo as maiores taxas de extensão micelial em todas as temperaturas avaliadas. $P$. middletonii restringiu-se a uma pequena faixa ótima de crescimento que foi entre 20 e $25^{\circ} \mathrm{C}$, visto que, em 15 e $30^{\circ} \mathrm{C}$, o isolado desenvolveu-se mais lentamente.

Tanto para o isolado de $P$. dissotocum, que não cresceu na temperatura de $40^{\circ} \mathrm{C}$, quanto para o isolado de P. middletonii, que não cresceu a partir de $35^{\circ} \mathrm{C}$, testes foram realizados transferindo as placas dos isolados não crescidos para as respectivas temperaturas ideais de crescimento. A temperatura de $35^{\circ} \mathrm{C}$ para P.middletonii, e $40^{\circ} \mathrm{C}$ para $P$. dissotocum, foram apenas temperaturas de inibição e não de morte, tendo sido observado o crescimento dos mesmos após 10 dias de incubação. Contudo, P.middletonii não sobreviveu na temperatura de $40^{\circ} \mathrm{C}$.

Middletoni (12) estudou o efeito de diferentes temperaturas no crescimento micelial de espécies de Pythium crescidas em CMA, dentre elas de Pythium dissotocum, tendo determinado $28^{\circ} \mathrm{C}$ como a temperatura ideal de crescimento, e $34^{\circ} \mathrm{C}$ como máxima do isolado estudado. No entanto, Plaats-Niterink (19), em BCA (batata-cenouraágar), verificou que a temperatura ótima de crescimento para $P$. dissotocum está compreendida entre $20-25^{\circ} \mathrm{C}$, com máxima de $35^{\circ} \mathrm{C}$ e, para $P$. middletonii, a temperatura ótima está entre $25-30^{\circ} \mathrm{C}$, com máxima de $35^{\circ} \mathrm{C}$. Diferenças no crescimento micelial podem ocorrer entre diferentes espécimes de uma mesma espécie de Pythium, principalmente levando-se em consideração os diferentes meios de
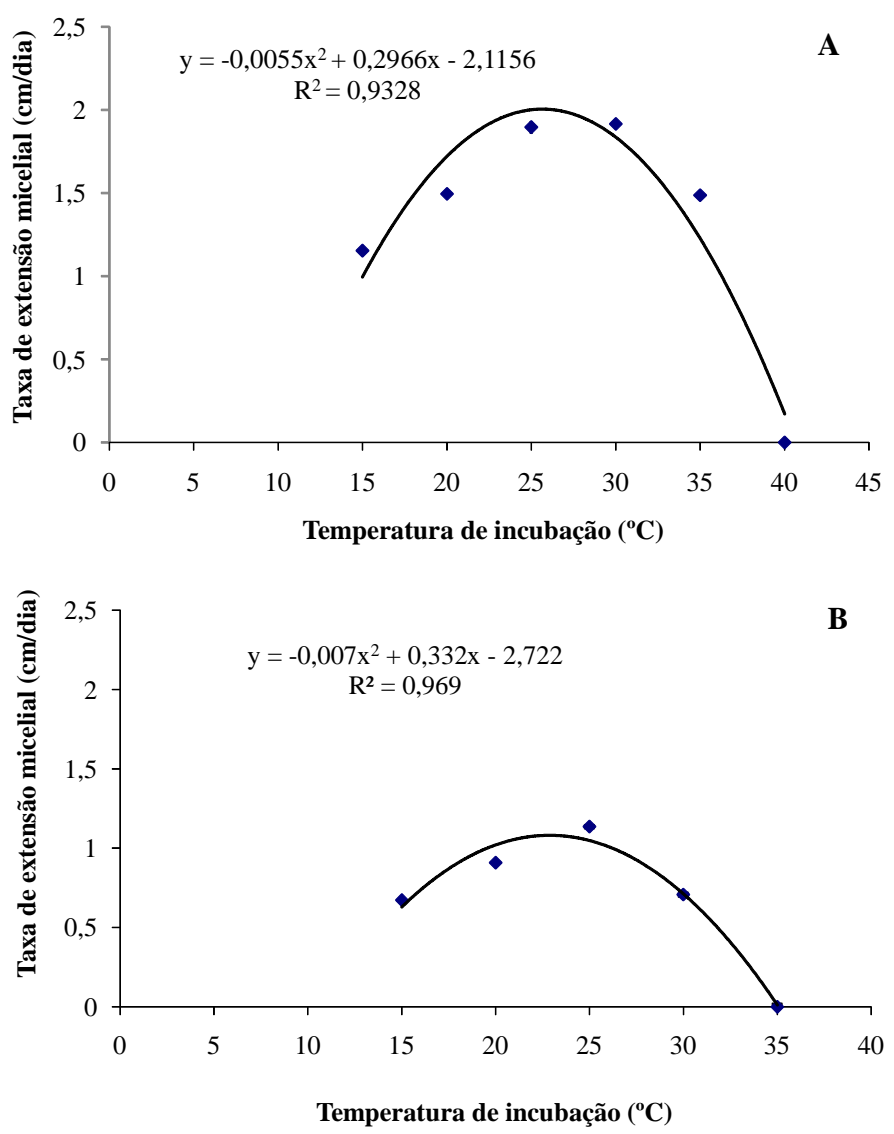

Figura 3. Influência da temperatura de incubação sobre a taxa de extensão micelial diária: Pythium dissotocum (A) e Pythium middletonii (B) 
cultura utilizados para este fim.

No Brasil, poucos foram os estudos sobre a influência da temperatura no crescimento micelial de Pythium spp. Teixeira et al. (25) estudaram a influência da temperatura sobre o crescimento micelial de três isolados de Pythium helicoides Drechsler $\left(\mathrm{H}_{1}, \mathrm{H}_{2}\right.$ e $\left.\mathrm{H}_{3}\right)$, cinco isolados pertencentes ao grupo $\mathrm{F}\left(\mathrm{F}_{1}\right.$ a $\left.\mathrm{F}_{5}\right)$ e quatro ao grupo $\mathrm{T}\left(\mathrm{T}_{1}\right.$ a $\mathrm{T}_{4}$ ), todos provenientes de culturas hidropônicas de alface, concluindo que a faixa de temperatura ótima para o crescimento micelial abrangeu desde 24 a $37^{\circ} \mathrm{C}$ para os isolados de $P$. helicoides e de 21 a $30^{\circ} \mathrm{C}$ para os isolados de Pythium pertencentes aos grupos $\mathrm{F}$ e T, com exceção de $\mathrm{F}_{4}$, que exibiu ótimo de temperatura entre 25 e $35^{\circ} \mathrm{C}$. Patekoski \& Pires-Zottarelli (17) estudando duas espécies de Pythium, P. aphanidermatum e $P$. dissotocum, isolados provenientes de raízes necrosadas de tabaco (Nicotiana tabacum L.) e de tomate (Lycopersicon esculentum), respectivamente, estabeleceram $31^{\circ} \mathrm{C}$ como temperatura ótima para o isolado de $P$. aphanidermatum, e $26^{\circ} \mathrm{C}$ para o de $P$. dissotocum, evidenciando que pequena variação ocorre na avaliação da temperatura ótima entre espécimes de uma mesma espécie.

\section{Avaliação patogênica in vitro de Pythium dissotocum e $P$. middletonii em quatro cultivares comerciais de alface}

Em $20^{\circ} \mathrm{C}$, avaliando-se o comprimento da radícula, a cultivar Mimosa foi considerada a menos suscetível a $P$. dissotocum, com diminuição da radícula em $70 \%$ em relação ao controle, enquanto Vera $(81 \%)$, Tainá $(78 \%)$ e Elisa $(81 \%)$ foram as mais suscetíveis, não havendo diferenças estatísticas entre o comprimento das mesmas. Quando considerado o comprimento do hipocótilo, Mimosa (43\%) e Tainá $(11 \%)$ foram as menos suscetíveis, e Vera (55\%) e Elisa $(56 \%)$ as mais suscetíveis (Tabela 1).

Para o isolado de P. middletonii, quando avaliado o comprimento da radícula, Vera e Mimosa foram consideradas menos suscetíveis, com diminuição da radícula em $22 \%$ e $26 \%$, respectivamente, em relação ao controle, e Tainá $(41 \%)$ e Elisa $(37 \%)$ as mais suscetíveis ao patógeno. Quanto ao comprimento do hipocótilo, Vera foi considerada a mais suscetível, com diminuição da radícula em $28 \%$ em relação ao controle, enquanto Mimosa, Tainá e Elisa não diferiram estatisticamente das testemunhas (Tabela 1).

Avaliando-se o comprimento da radícula, em $20^{\circ} \mathrm{C}$, foi possível observar que os tratamentos inoculados com os espécimes de $P$. dissotocum e $P$. middletonii, diferiram estatisticamente das testemunhas,

Tabela 1. Avaliação do efeito patogênico in vitro de Pythium dissotocum e $P$. middletonii, na temperatura de $20^{\circ} \mathrm{C}$, sobre quatro cultivares de alface, com base nos comprimentos de radícula e de hipocótilo (*).

\begin{tabular}{lcccc}
\hline & \multicolumn{4}{c}{ Cultivares } \\
\cline { 2 - 6 } & Mimosa & \multicolumn{4}{c}{ Vera } & Tainá & Elisa \\
\hline Controle & $6,34 \mathrm{dC}$ & $4,72 \mathrm{bC}$ & $3,28 \mathrm{aC}$ & $5,68 \mathrm{cC}$ \\
P.dissotocum & $1,92 \mathrm{bA}$ & $0,88 \mathrm{aA}$ & $0,82 \mathrm{aA}$ & $1,10 \mathrm{aA}$ \\
P. middletonii & $4,66 \mathrm{cB}$ & $3,68 \mathrm{bB}$ & $1,94 \mathrm{aB}$ & $3,58 \mathrm{bB}$ \\
\hline \multicolumn{5}{c}{ Comprimento de hipocótilo (cm) } \\
\hline Controle & $0,84 \mathrm{bB}$ & $0,58 \mathrm{aC}$ & $0,54 \mathrm{aA}$ & $0,50 \mathrm{aB}$ \\
P.dissotocum & $0,48 \mathrm{bA}$ & $0,26 \mathrm{aA}$ & $0,48 \mathrm{bA}$ & $0,22 \mathrm{aA}$ \\
P. middletonii & $0,80 \mathrm{bB}$ & $0,42 \mathrm{aB}$ & $0,52 \mathrm{aA}$ & $0,48 \mathrm{aB}$ \\
\hline
\end{tabular}

*Letras minúsculas comparam na horizontal e maiúsculas comparam na vertical, dentro de cada parâmetro. Médias seguidas da mesma letra não diferem entre si em nível de 5\% pelo teste de Tukey. apresentando patogenicidade em relação a todas as cultivares estudadas.

Através da visualização da sintomatologia, foi possível verificar, em todas as cultivares, que o isolado de $P$. dissotocum foi o mais agressivo, sendo responsável pela inibição da formação de raízes laterais e necrose acentuada da raiz principal. No entanto, para $P$. middletonii não foi observada sintomatologia nas cultivares analisadas. Tanto o isolado de $P$. dissotocum, como o de $P$. middletonii, não ocasionaram a morte das plântulas inoculadas à $20^{\circ} \mathrm{C}$.

Para P. middletonii, em sua temperatura ideal de crescimento $\left(23^{\circ} \mathrm{C}\right)$, foi verificada uma diminuição significativa das radículas (Vera e Elisa) e hipocótilos (Mimosa e Vera) (Tabela 2), no entanto nenhuma sintomatologia de podridão foi verificada.

Para P. dissotocum, a temperatura ideal de crescimento $\left(27^{\circ} \mathrm{C}\right)$, foi responsável pela baixa porcentagem de plântulas sobreviventes entre as cultivares, sendo que, a porcentagem mais baixa (54\%) foi verificada na cultivar Vera, considerada entre as cultivares, a mais suscetível, com a cultivar Mimosa apresentando maior porcentagem de plântulas sobreviventes. Com relação ao comprimento das radículas, Mimosa foi considerada a menos suscetível, com diminuição da radícula em $61 \%$ em relação ao controle, e Tainá (38\%) quando analisado o comprimento dos hipocótilos. Somente a cultivar Mimosa apresentou diferença significativa com as demais cultivares nos dois últimos parâmetros analisados, ressaltando-se também que nestes parâmetros todos os tratamentos apresentaram diferenças significativas em relação às testemunhas (Tabela 3 ).

A severidade da doença foi significativamente mais elevada na temperatura de $27^{\circ} \mathrm{C}$, mostrando, em todas as cultivares, uma grande agressividade do espécime, ocasionando inibição da formação de raízes laterais, necrose das pontas das raízes principais e laterais e, necrose acentuada na raiz principal. As plântulas não inoculadas apresentaram menor desenvolvimento e quantidade de raízes laterais que aquelas cultivadas a $20^{\circ} \mathrm{C}$, evidenciando que temperaturas mais altas prejudicam o desenvolvimento de plântulas de alface.

Os parâmetros avaliados (comprimento da radícula, do hipocótilo e plântulas sobreviventes) parecem ter sido apropriados para a avaliação patogênica de espécies de Pythium in vitro. Segundo Teixeira et al. (25), a massa fresca das plântulas inoculadas não foi um parâmetro adequado para a avaliação da patogenicidade in vitro, evidenciando pouquíssimas diferenças entre os tratamentos.

Pythium middletonii provocou redução no comprimento das radículas e hipocótilos mesmo na ausência de sintomas de podridão radicular. Segundo Stanghellini \& Kronland (20), essas condições são

Tabela 2. Avaliação do efeito patogênico in vitro de Pythium middletonii, na temperatura de $23^{\circ} \mathrm{C}$, sobre quatro cultivares de alface, com base nos comprimentos de radícula e de hipocótilo $(*)$.

\begin{tabular}{lcccc}
\hline & \multicolumn{4}{c}{ Cultivares } \\
\cline { 2 - 5 } & Mimosa & Vera & Tainá & Elisa \\
\hline Controle & $5,72 \mathrm{bA}$ & $6,16 \mathrm{bB}$ & $4,00 \mathrm{aA}$ & $5,58 \mathrm{bB}$ \\
P. middletonii & $5,24 \mathrm{bA}$ & $3,68 \mathrm{bA}$ & $3,70 \mathrm{aA}$ & $4,22 \mathrm{aA}$ \\
\hline & \multicolumn{4}{c}{ Comprimento de hipocótilo $(\mathbf{c m})$} \\
\hline Controle & $0,92 \mathrm{bB}$ & $0,46 \mathrm{aB}$ & $0,44 \mathrm{aA}$ & $0,40 \mathrm{aA}$ \\
P. middletonii & $0,80 \mathrm{bA}$ & $0,34 \mathrm{aA}$ & $0,40 \mathrm{aA}$ & $0,44 \mathrm{aA}$ \\
\hline
\end{tabular}

*Letras minúsculas comparam na horizontal e maiúsculas comparam na vertical, dentro de cada parâmetro. Médias seguidas da mesma letra não diferem entre si em nível de 5\% pelo teste de Tukey. 
chamadas de infecções subclínicas e levam a uma redução no desenvolvimento da planta, sem a exibição de sintomas óbvios da doença, mas que podem causar prejuízos nos cultivos hidropônicos.

A influência da temperatura nos espécimes de Pythium é um fator estudado por diversos autores ao redor do mundo $(6,7,12,15,17,19$,

Tabela 3. Avaliação do efeito patogênico in vitro de Pythium dissotocum, na temperatura de $27^{\circ} \mathrm{C}$, sobre quatro cultivares de alface, com base nos comprimentos de radícula e de hipocótilo e na sobrevivência das plântulas (*).

\begin{tabular}{lcccc}
\hline & \multicolumn{4}{c}{ Cultivares } \\
\cline { 2 - 5 } & Mimosa & Vera & Tainá & Elisa \\
\hline Controle & $4,88 \mathrm{bB}$ & $4,22 \mathrm{bB}$ & $2,86 \mathrm{aB}$ & $4,54 \mathrm{bB}$ \\
P. dissotocum & $1,88 \mathrm{bA}$ & $0,54 \mathrm{aA}$ & $0,76 \mathrm{aA}$ & $0,98 \mathrm{aA}$ \\
\hline \multicolumn{5}{c}{ Comprimento de hipocótilo (cm) } \\
\hline Controle & $0,88 \mathrm{bB}$ & $0,46 \mathrm{aB}$ & $0,50 \mathrm{aB}$ & $0,50 \mathrm{aB}$ \\
P. dissotocum & $0,46 \mathrm{bA}$ & $0,24 \mathrm{aA}$ & $0,31 \mathrm{aA}$ & $0,26 \mathrm{aA}$ \\
\hline \multicolumn{5}{c}{ Plântulas sobreviventes $(\%)$} \\
\hline Controle & $100 \mathrm{aA}$ & $100 \mathrm{aB}$ & $100 \mathrm{aB}$ & $100 \mathrm{aA}$ \\
P. dissotocum & $89 \mathrm{bA}$ & $54 \mathrm{aA}$ & $69 \mathrm{abA}$ & $86 \mathrm{bA}$ \\
\hline
\end{tabular}

*Letras minúsculas comparam na horizontal e maiúsculas comparam na vertical, dentro de cada parâmetro. Médias seguidas da mesma letra não diferem entre si em nível de 5\% pelo teste de Tukey.

26) podendo estar relacionada com o crescimento micelial, formação das estruturas reprodutivas, patogenicidade e desenvolvimento de doenças radiculares. Segundo Ribeiro (20), a temperatura é um parâmetro crítico para o desenvolvimento de propágulos infectivos de fitopatógenos.

Ingram \& Cook (10) estudaram o efeito da temperatura na incidência de "damping-off" de pré-emergência em diversos hospedeiros, $\operatorname{com} P$. ultimum var. sporangiferum causando "damping-off" em trigo (Triticum aestivum L.), nas temperaturas compreendidas entre $15 \mathrm{e}$ $25^{\circ} \mathrm{C}$, em lentilhas (Lens culinaris Medik.) entre 10 e $25^{\circ} \mathrm{C}$ e, em ervilhas (Pisum sativum L.) entre 5 e $25^{\circ} \mathrm{C}$. Esses autores concluíram que, a manifestação da doença causada por um mesmo espécime de Pythium, depende da temperatura e dos hospedeiros envolvidos. PlaatsNiterink (19) relata, "Quando condições são favoráveis para o fungo, mas não são favoráveis para o hospedeiro, espécies de Pythium podem tornar-se muito patogênicas". Isto reflete claramente as condições demonstradas no presente estudo, no qual $P$. dissotocum, em sua temperatura ideal de crescimento, mostrou uma elevada patogenicidade, em condições relativamente desfavoráveis para o crescimento da alface.

Em estudo realizado por Teixeira et al. (25) ficou evidenciado o efeito da temperatura no potencial patogênico de Pythium spp. na cultivar de alface Verônica, onde isolados de P. helicoides, em $30^{\circ} \mathrm{C}$, foram notadamente os mais patogênicos, ocasionando $100 \%$ de mortalidade das sementes logo após sua germinação, enquanto a $21^{\circ} \mathrm{C}$, todos os isolados induziram subdesenvolvimento de plântulas, acompanhado ou não de necrose dos tecidos radiculares.

De maneira geral, verificou-se neste estudo que a cultivar crespa foi mais suscetível aos patógenos estudados que as do tipo mimosa e lisa, o mesmo tendo sido observado por Pinto et al. (16) em estudo com $P$. helicoides. Conforme pesquisa realizada na região de Mogi das Cruzes, maior centro paulista de produção de alface, o mercado consumidor de folhas crespas gira em torno de $70 \%$ no estado de São Paulo, evidenciando que a cultivar crespa é uma das mais importantes para o mercado brasileiro (9). Essas informações demonstram que com a expansão dos cultivos hidropônicos, há a necessidade de pesquisas visando à obtenção de cultivares de alface crespa com maior resistência aos patógenos, especialmente a Pythium spp.

Os resultados deste estudo in vitro evidenciam a necessidade de experimentos adicionais in vivo, de forma a complementar as informações essenciais para o entendimento do potencial patogênico de espécies de Pythium em cultivares de alface em sistemas hidropônicos.

\section{AGRADECIMENTOS}

À Fundação de Amparo à Pesquisa do Estado de São Paulo (FAPESP) pelo auxílio financeiro na forma de concessão de bolsa de Mestrado ao primeiro autor (Processo FAPESP 05/52894-9).

\section{REFERÊNCIAS BIBLIOGRÁFICAS}

1. Carvalho, I.; Milanez, A.I. Efeitos da temperatura e umidade de solo sobre Pythium splendens. Revista de Microbiologia, São Paulo, v.20, n.4, p.477-482, 1989.

2. Drechsler, C. Some new species of Pythium. Journal of the Washington Academy of Sciences, Washington DC., v.20, p.398-418, 1930.

3. Figueiredo, M.B. Estudos sobre a aplicação do método de Castellani para conservação de fungos patógenos em plantas. O Biológico, São Paulo, v. 33, p.9-13, 1967.

4. Furlani, P.R. Hidroponia. Boletim Técnico IAC, Campinas, n.100, p.285, 1996.

5. Furlani, P.R. Hydroponic vegetable production in Brazil. Acta Horticulturae, The Hague, v.481, p.777-778, 1999.

6. Frezzi, M.J. Espécies de Pythium fitopatógenas identificadas en la República Argentina. Revista de Investigaciones Agrícolas, Buenos Aires, v.10, p.113-241, 1956.

7. Herrero, M.L.; Hermansen, A.; Elen O.N. Occurrence of Pythium spp. and Phytophthora spp. in Norwegian Greenhouses and their Pathogenicity on Cucumber Seedlings. Journal of Phytopathology, Berlin, v.151, p.36-41, 2003.

8. Hidrogood. Sobre hidroponia. Disponível em: <http:// www.hidrogood.com.br>. Acesso em: 11 jan. 2007.

9. Horticeres. Horticeres lança nova cultivar de alface crespa. Disponível em: < http://www.horticeres.com.br>. Acesso em: 3 mar. 2007.

10. Ingram, D.M.; Cook, R.J. Pathogenicity of four Pythium species to wheat, barley, peas and lentils. Plant Pathology, London, v.39, p.110-117, 1990.

11. Labhidro. Hidroponia. Disponível em: <http://www.labhidro. cca.ufsc.br>. Acesso em: 18 nov. 2006.

12. Middleton, J.T. The taxonomy, host range and geographic distribution of the genus Pythium. Memoirs of the Torrey Botanical Club, Durham, v.20, p.1-171, 1943.

13. Milanez, A.I. Fungos de águas continentais. In: Fidalgo, O.; V.L.R. Bononi (Coord.). Técnicas de coleta, preservação e herborização de material botânico. São Paulo: Instituto de Botânica, 1989. p. 17-20.

14. Nascimento, W.M.; Cantliffe, D.J. Germinação de sementes de alface sob altas temperaturas. Horticultura Brasileira, Brasília, v.20, n.1, p.103-106, 2002 .

15. Owen-Going, N.; Sutton, J.C.; Grodzinski, B. Relationships of Pythium isolates and sweet pepper plants in single-plant hydroponic units. Canadian Journal of Plant Pathology, Ottawa, v. 25, n.2, p.155-167, 2002.

16. Pinto, Z.V.; Sousa, A.L.O.P.; Silva, C.P.; Duarte, D.G.; Patrício, F.R.A.; Santos, A.S.; Teixeira, L. D. Reação de cultivares de alfa- 
ce à podridão de raízes, causada por Pythium helicoides, em sistemas hidropônicos. Summa Phytopathologica, Botucatu, v.31. p. 96-96, 2005.

17. Patekoski, K.S. \& Pires-Zottarelli, C.L.A. Patogenicidade in vitro de Pythium aphanidermatum e Pythium dissotocum em variedades de alface (Lactuca sativa L.). Hoehnea, São Paulo, v.36, n.1, p.161-172, 2009.

18. Patekoski, K.S. \& Pires-Zottarelli, C.L.A. Patogenicidade de Pythium aphanidermatum a alface cultivada em hidroponia e seu bioncontrole com Trichoderma. Pesquisa Agropecuária Brasileira, Brasília, v.45, n.8, p. 805-810, 2010.

19. Plaats-Niterink, A.J. van der. Monograph of the genus Pythium. Studies in Mycology, Baarn, v. 1, p.1-242, 1981.

20. Ribeiro, O.K. Physiology of asexual sporulation and spore germination in Phytophthora. In: Erwin, D.C.; Bartnicki-Garcia, S.; Tsao, P.H. (Ed.). Phytophthora: its biology, taxonomy, ecology and pathology. St Paul, APS Press, 1983. p. 55-70.

21. Rodrigues, L.R.F. Técnicas de cultivo hidropônico e de controle ambiental no manejo de pragas, doenças e nutrição vegetal em ambiente protegido. Jaboticabal: FUNEP, 2002. v. 1, 765p.

22. Stanghellini, M.E.; Kronland, W.C. Yield loss in hydroponically grown lettuce attributed to subclinical infection of feeder rootlets by Pythium dissotocum. Plant Disease, St. Paul, v.70, n.11, p. 1053-1056, 1986 .
23. Sutton, J.C.; Sopher, C.R.; Owen-Going, T.N.; Liu, W.; Grodzinsk, B.; Hall, J.C.; Benchimol, R.L. Etiology and epidemiology of Pythium root rot in hydroponic crops: current lnowledge and perspectives. Summa Phytopathologica, Botucatu, v.32, n. 4, p.307-321, 2006.

24. Teixeira-Yañez, L.D. Identificação, Patogenicidade e Sensibilidade a produtos químicos in vitro de espécies de Pythium de cultura hidropônica de alface (Lactuca sativa L.). 2000. 74f. Dissertação (Mestrado em Fitopatologia): Escola Superior de Agricultura Luiz de Queiroz, Universidade de São Paulo, Piracicaba.

25. Teixeira, L.D.; Pires-Zottarelli, C.L.A.; Kimati, H. Efeito da temperatura no crescimento micelial e patogenicidade de Pythium spp. que ocorrem em alface hidropônica no Brasil. Summa Phytopathologica, Botucatu, v.32, n.3, p.221-226, 2006.

26. Utkhede, R.S.; Levesque, C.A.; Dinh. D. Pythium aphanidermatum root rot in hydroponically grown lettuce and the effect of chemical and biological agents on its control. Canadian Journal of Plant Pathology, Ottawa, v.22, n.2, p.138-144, 2000.

27. Vanachter, A. Development of Olpidium and Pythium in the nutrient solutions of NFT grown lettuce, and possible control methods. Acta Horticulturae, The Hague, v.382, p.187-196, 1995.

28. Waterhouse, G. 1967. Key to Pythium Pringsheim. Mycological Papers, Kew, v.109, n.1, p.1-15, 1967. 